\title{
RESGATE ARQUEOLÓGICO DOS SÍTIOS EVANGELISTA E IGREJINHA, EM
} PRADOS/MG

ARCHAEOLOGICAL RESCUE OF EVANGELISTA AND IGREJINHA SITES, IN PRADOS/MG

Paulo Eduardo de Oliveira Enéas Inês de Oliveira Noronha

Como citar este artigo:

ENÉAS, Paulo eduardo de Oliveira \& NORONHA, Inês de Oliveira. Resgate arqueológico dos sítios Evangelista e Igrejinha, em Prados/MG. Cadernos do Lepaarq, v. XVII, n.33, p. 251-269, Jan-Jun. 2020. 


\title{
Resgate arqueológico dos sítios Evangelista e Igrejinha, em Prados/ $\mathrm{MG}^{\text {a }}$
}

\author{
Paulo Eduardo de Oliveira Enéas ${ }^{\mathrm{b}}$ \\ Inês de Oliveira Noronha ${ }^{c}$
}

\begin{abstract}
Resumo: O presente relatório visa divulgar os resultados obtidos com a realização do Resgate Arqueológico no âmbito do licenciamento ambiental para a ampliação do empreendimento Mina Fazenda Invernada e Mata do Ribeirão, em Prados/MG. Os trabalhos foram realizados em um sítio histórico e em três sítios arqueológicos cerâmicos, dentre eles o SAPH Evangelista e o SAPH Igrejinha, objetos deste texto.
\end{abstract}

\section{Palavras Chave:}

Arqueologia Pré-colonial, Evangelista, Igrejinha, Licenciamento Ambiental.

\begin{abstract}
This report brings the results obtained with the execution of the Archaeological Rescue in the scope of environmental licensing for the expansion of the Fazenda Invernada and Mata do Ribeirão project in Prados/MG. The works were carried out in a historical site and three ceramic archaeological sites, among them the SAPH Evangelista and SAPH Igrejinha, objects of this text.
\end{abstract}

a A equipe responsável pelo Resgate foi: Paulo Eduardo de Oliveira Enéas (Arqueólogo Coordenador); Ádila Borges Figueira Cerqueira (Arqueóloga); Julimar Quaresma Mendes Júnior (Arqueólogo); Inês de Oliveira Noronha (Arqueóloga); Virginia Barbosa Pereira (Arqueóloga); Leonardo Ribeiro dos Santos (Técnico em Arqueologia); Kleber Antônio Fraga (Técnico em Arqueologia); Marlon Washington da Silva (Técnico em Arqueologia).

b Socioambiental Projetos. Graduação em Arqueologia. Setor de Arqueologia, Belo Horizonte/MG, Brasil. E-mail: <pauloeneas@gmail.com>.

Socioambi-ental Projetos.

c Doutora em Educação e Pós-graduada em Arqueologia e Patrimônio. Setor de Arqueologia, Belo Horizonte/MG, Brasil. E-mail:

<ines.noronha@uol.com.br>. 


\section{INTRODUÇÃO}

A consultoria responsável realizou, durante o ano de 2016, o resgate arqueológico dos sítios a serem impactados com a ampliação de empreendimento minerário, locado no município de Prados/MG. Foram alvo de resgate os seguintes sítios: Sítio Arqueológico Pré-Histórico (SAPH) Evangelista; Sítio Arqueológico Pré-Histórico (SAPH) Igrejinha; Sítio Arqueológico Multicomponencial (SAM) Ribeirão do Elvas; e Sítio Arqueológico Histórico (SAH) Conjunto de Canais Históricos. A pesquisa foi executada a fim de salvaguardar os bens culturais a serem impactados pela ampliação do empreendimento, assim como a atender à legislação atinente ao licenciamento ambiental, conforme solicitado pelo IPHAN, através do ofício $n^{\circ}$ 1698/2015.

Nessa empreitada, partimos da premissa de que o patrimônio arqueológico constitui herança cultural da nação, pois se trata do registro físico das atividades desenvolvidas pelos diferentes atores que participaram da formação da nossa sociedade. O seu gerenciamento e a sua proteção perpassam pela realização de estudos capazes de gerar novos dados e de oferecer à comunidade elementos para a identificação de suas raízes culturais e sociais (MORAIS, 2006).

Neste artigo, apresentam-se os dados coletados do resgate arqueológico dos sítios Evangelista e Igrejinha, assim como as informações levantadas durante as análises laboratoriais.

\section{O Resgate do Sítio Arqueológico Evangelista}

O SAPH Evangelista se encontra na ADA do empreendimento, UTM 23K 596624/7655950, emárea de vertentede baixa declividade, em local de cultura de eucalipto, medindo, aproximadamente, 1,2 ha. Os primeiros vestígios cerâmicos foram encontrados durante a realização do levantamento sistemático prospectivo, em uma tradagem, entre $0-30 \mathrm{~cm}$ de profundidade. Os fragmentos eram pequenos, e um deles possuía engobo vermelho. Posteriormente, para delimitação espacial, novas intervenções em subsuperfície foram realizadas, sendo que seis apresentaram resultado positivo.

Através de análises prévias, decidiu-se por realizar um resgate amostral, atentando-se para as áreas de maior concentração de material, representadas por concentrações em superfície e por tradagens e sondagem positiva. Tal área loca-se, aproximadamente, na região central do sítio arqueológico. Assim, optou-se por realizar escavações por meio de quadrículas de $1 \mathrm{~m}^{2}$, em malha de 10 m equidistantes, na área de concentração (Figura 1). Vale ressaltar que esse método já foi aplicado por diversos pesquisadores, dentre eles: Viana (1996), Melo (1999) e Scientia $(2002,2005)$. 


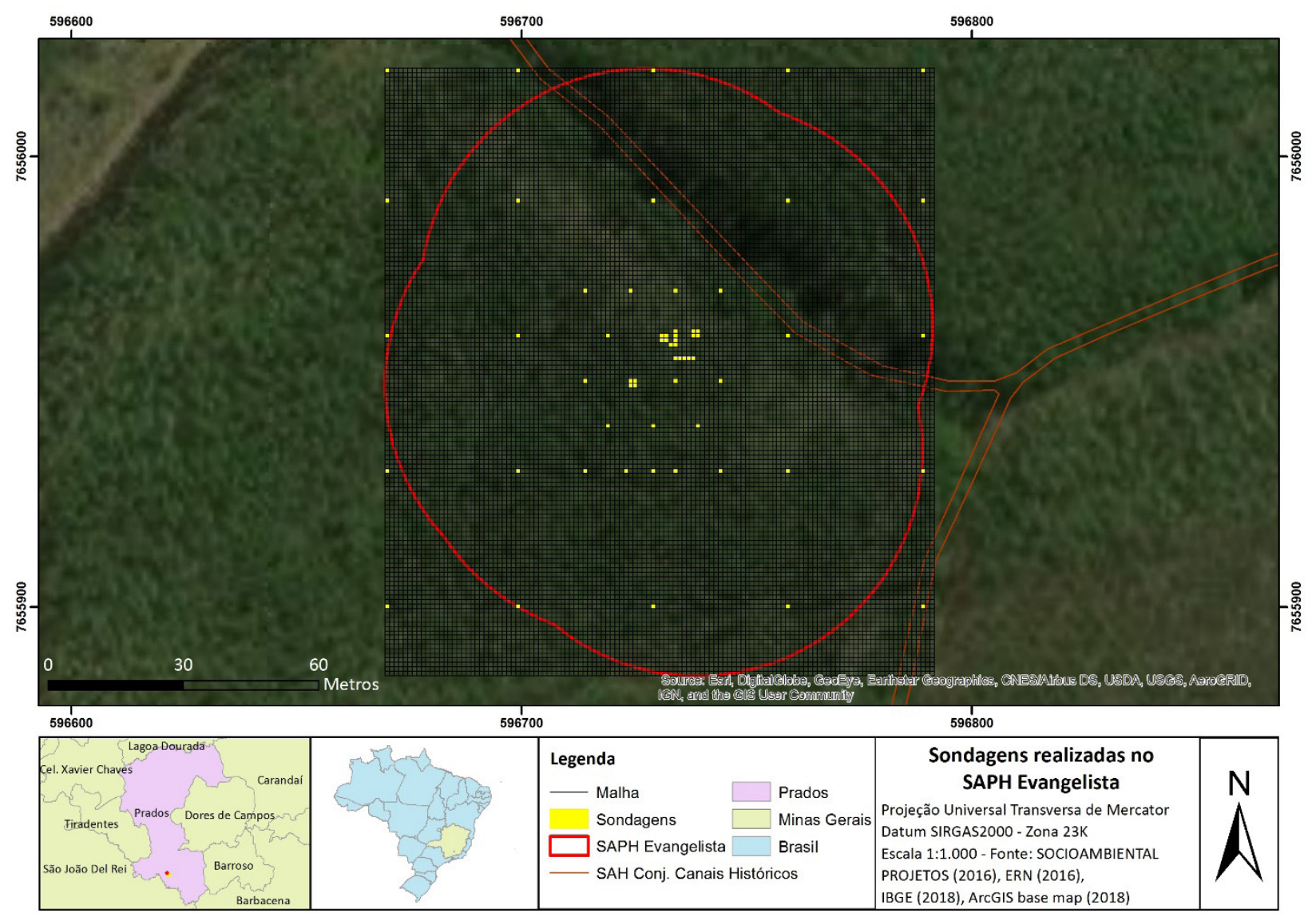

Figura 1: Localização do SAPH Evangelista.

Dessa forma, iniciaram-se as atividades com a plotagem da malha, na forma alfa (sentido W-E) - numérica (sentido N-S), do sítio arqueológico. Cabe ressaltar que não foi possível executar uma coleta superficial georreferenciada inicial visto a grande quantidade de serapilheira na totalidade da área do sítio. Foram iniciadas as escavações das 18 sondagens de $1 \mathrm{~m}^{2}$, com espaçamento de 10 metros equidistantes. Todas as unidades de escavação foram executadas com níveis artificiais de $10 \mathrm{~cm}$ e aprofundadas até $40 \mathrm{~cm}$ ou um nível estéreo $(10 \mathrm{~cm})$, sendo todos os níveis peneirados, independentemente destes serem positivo ou estéril (Figura 2). 

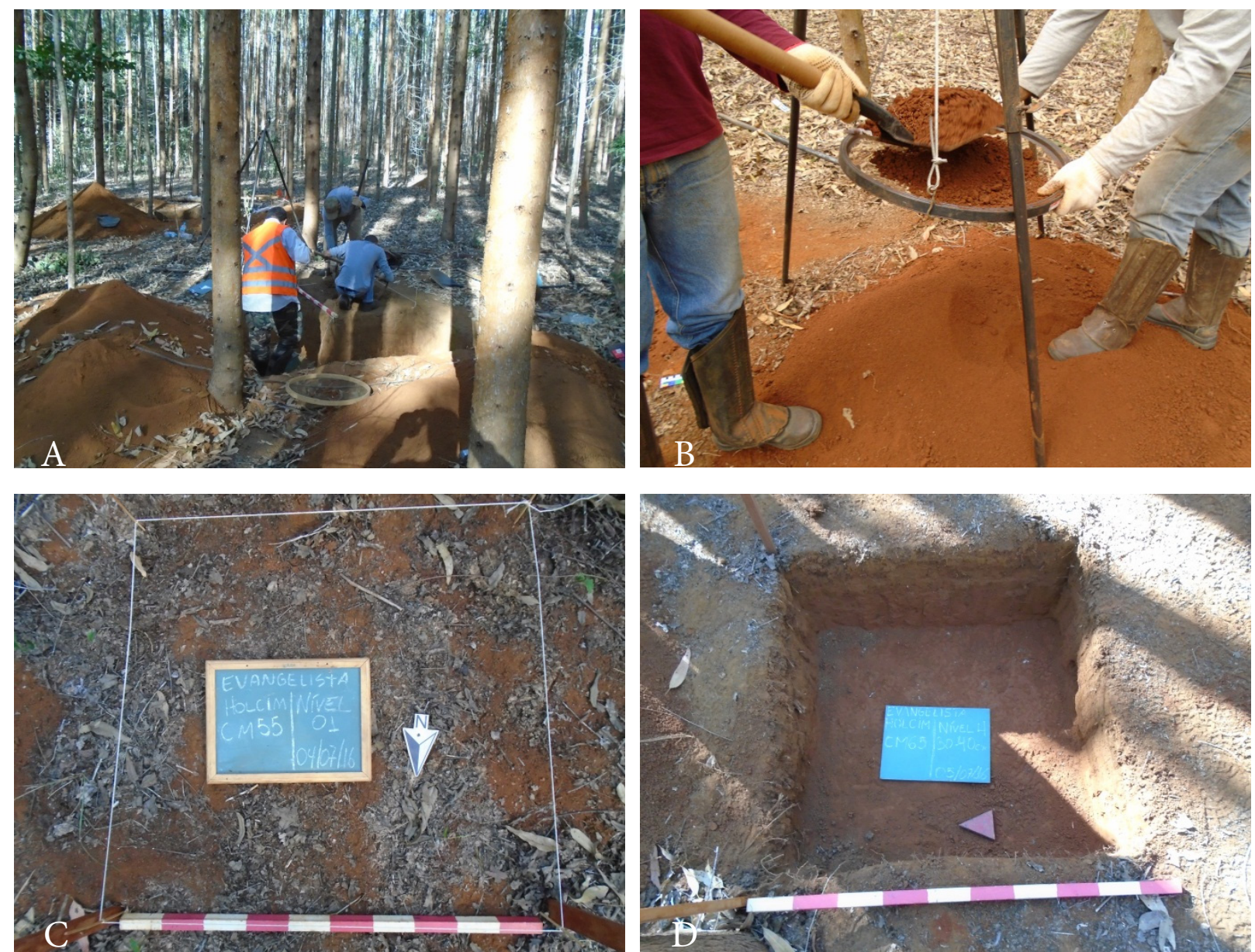

Figura 2: Abertura de sondagens.

A-B: Equipe realizando a abertura das sondagens. C-D: Sondagens abertas.

Finalizadas as sondagens propostas, foram plotadas novas unidades de escavação com espaçamento de 30 metros equidistantes (totalizando 23), com o intuito de identificar novas áreas de concentração e delimitar a dispersão de material arqueológico. Como resultado disso, chegouse à conclusão de que a concentração de material está locada apenas na área central do sítio. Visto isso, as sondagens que apresentaram o maior retorno de material cerâmico foram expandidas em sondagens de $4 m^{2}$, além da abertura de duas trincheiras de 5 metros $-5 m \times 1 m$ (Figura 3).
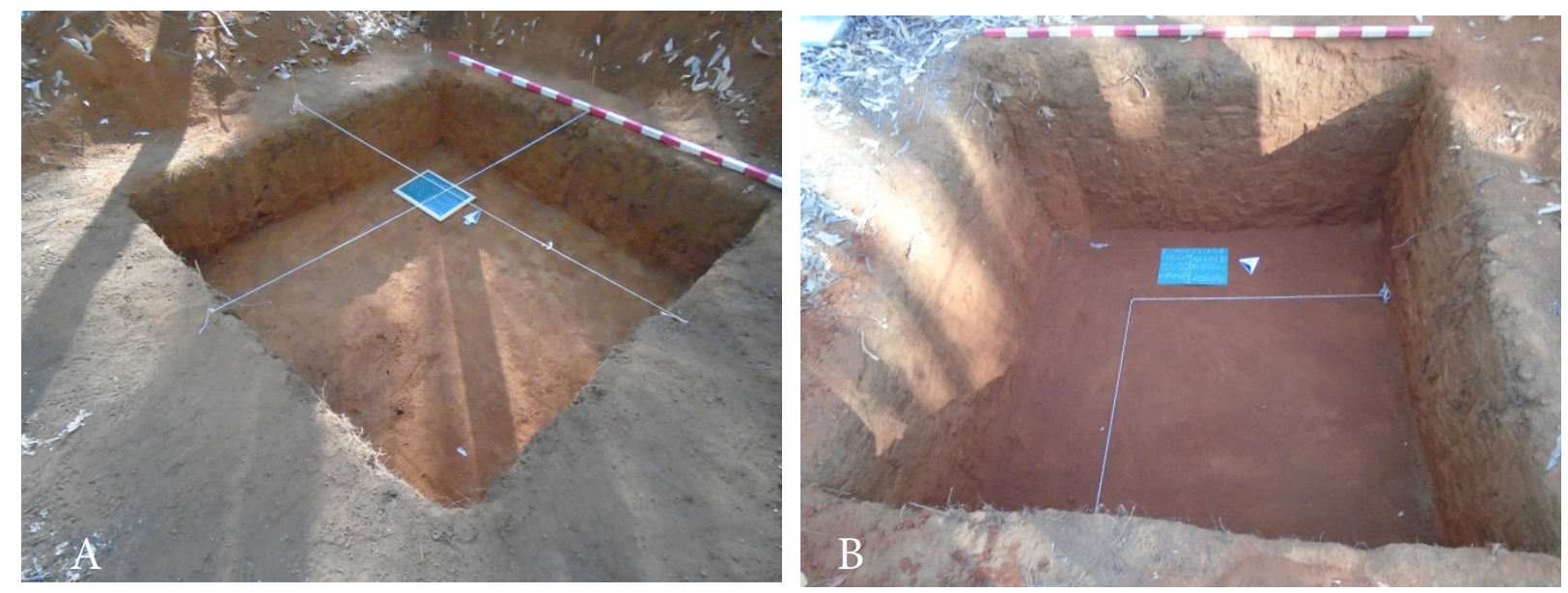

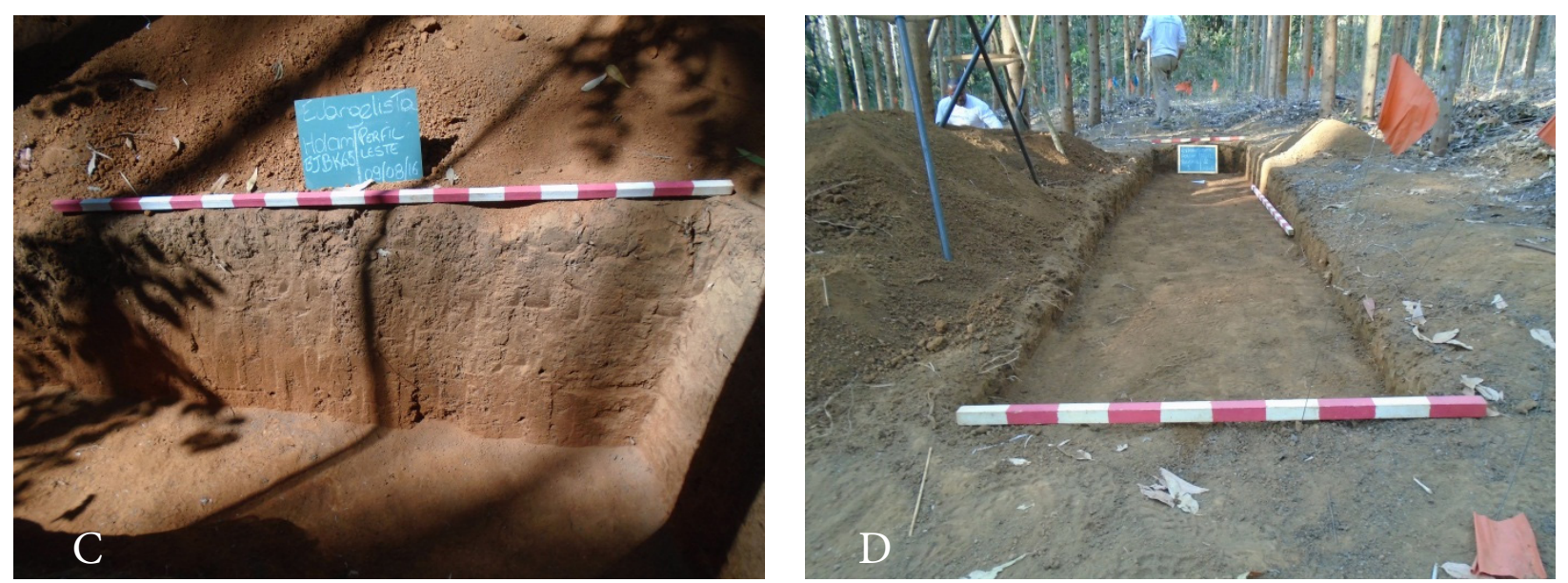

Figura 3: Unidades de escavação ampliadas.

O resultado retornado das escavações de ampliação de sondagens e trincheiras foi o esperado, apresentando uma grande quantidade de fragmentos cerâmicos, principalmente nos primeiros níveis (Figura 4).
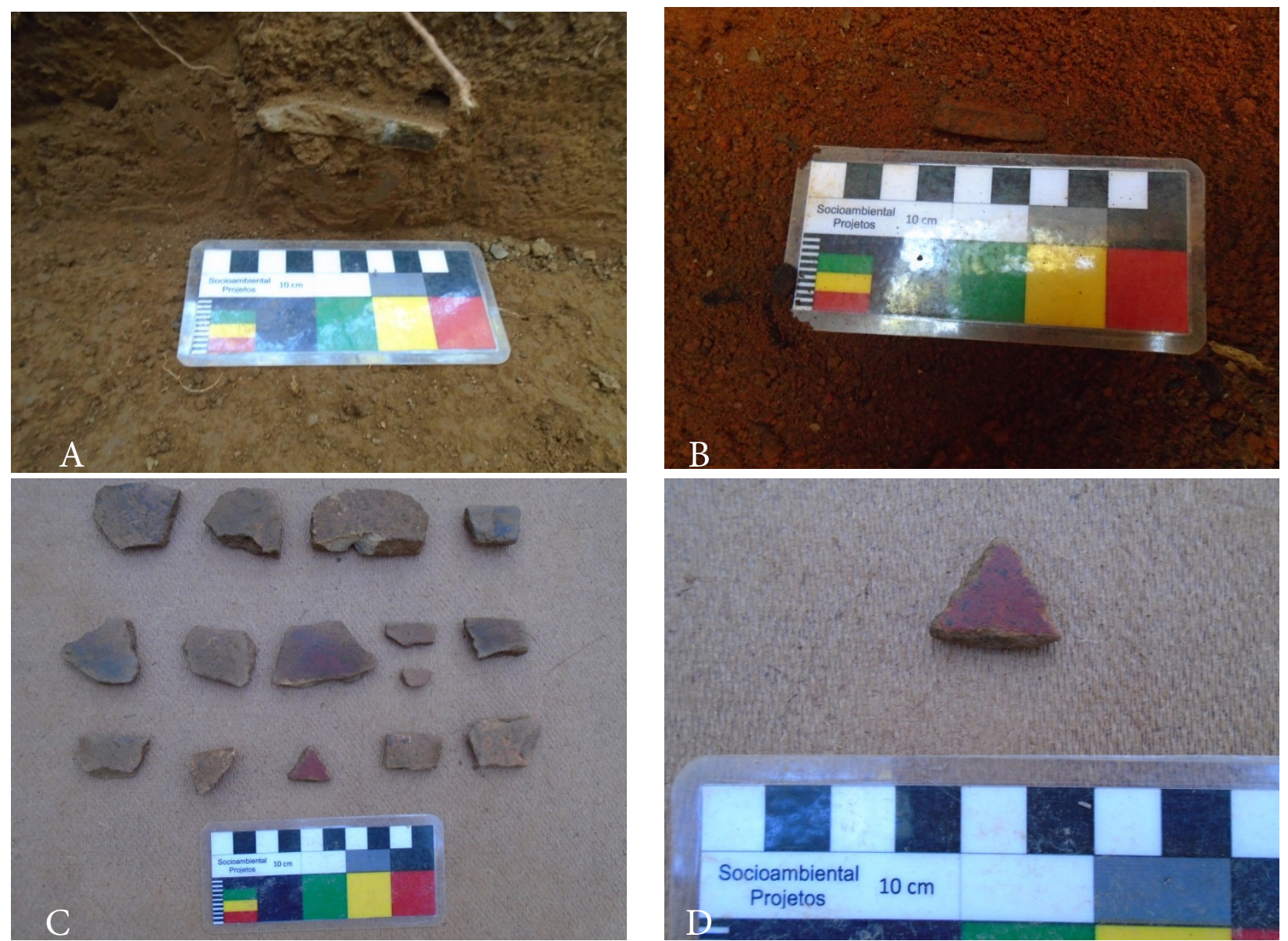

Figura 4: Vestígios arqueológicos.

Do total de 61 unidades de escavação abertas, 83,6\% apresentaram resultado positivo em um ou mais níveis quanto à presença de material arqueológico. Destas unidades de escavação e material em superfície, foram exumados 1.258 fragmentos cerâmicos e um fragmento de louça. A cerâmica se caracteriza por modo de produção acordelado; acabamento polido e/ou engobo 
vermelho; núcleo escuro ou núcleo central escuro; antiplástico mineral.
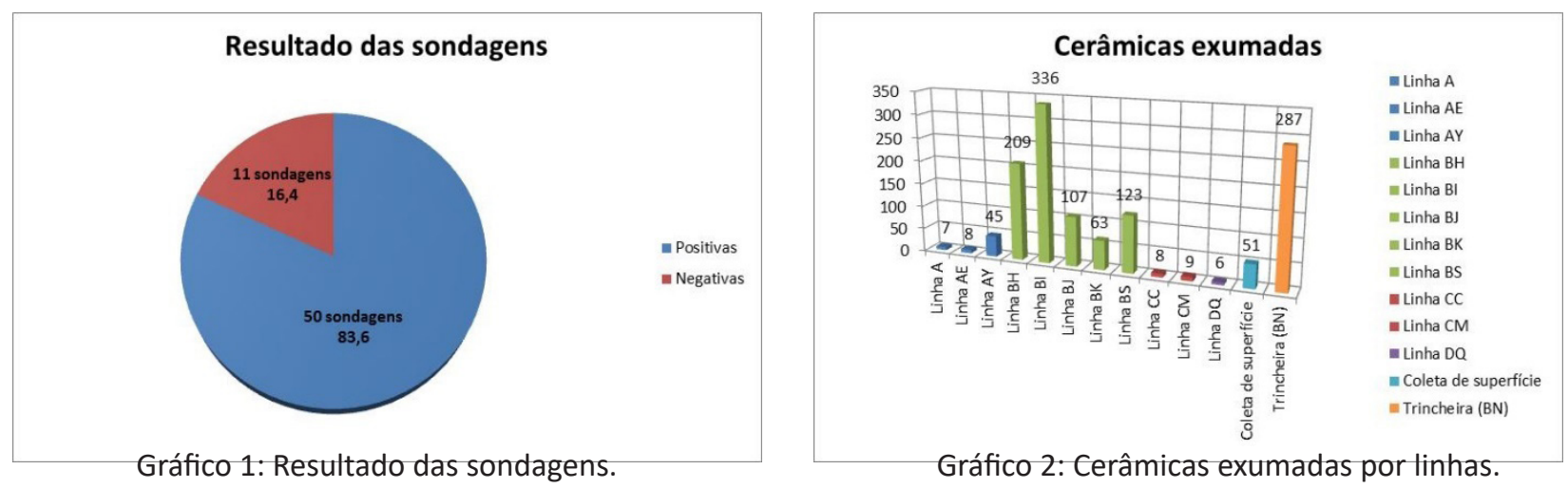

Há uma maior concentração de cerâmicas locadas na linha "B", no terço médio do sítio arqueológico. No material arqueológico predominante foi encontrado bastante fragmentado devido às constantes ações de preparo de terra para pasto e plantio de eucalipto. Devido ao arado, os vestígios encontrados nos três primeiros níveis sofreram maior impacto, visto o revolvimento de solo, elevando os materiais de $0-20 \mathrm{~cm}$ e rebaixando os de $20-30 \mathrm{~cm}$.

Como pôde se perceber, a camada arqueológica, na maior parte do sítio, limita-se aos três primeiros níveis, sendo que em poucas sondagens foram encontrados vestígios arqueológicos abaixo de $40 \mathrm{~cm}$. Foram coletados dois fragmentos cerâmicos para datação por termoluminescência (Trincheira BN65-69, nível 2 / BJ71, nível 2). Para tais fragmentos, foram apresentadas as seguintes datações:

\begin{tabular}{|c|c|c|c|c|}
\hline Cód. Datação & Amostra & Dose Anual & Dose Acumulada & Idade (anos) \\
\hline \multicolumn{5}{|c|}{ Datação do Resgate Arqueológico } \\
\hline 4678 & BJ 71 - $10-20 \mathrm{~cm}$ & $6.260 \pm 620$ & 2,3 & $370 \pm 55$ \\
\hline 4679 & Trincheira BN 65-69 - 10-20 cm & $6.080 \pm 600$ & 1,5 & $250 \pm 35$ \\
\hline \multicolumn{5}{|c|}{ Datação da Prospecção Arqueológica } \\
\hline 4382 & Sítio Evangelista - 10-20 cm & $3.300 \pm 410$ & 1,1 & $335 \pm 55$ \\
\hline
\end{tabular}

Tabela 1: Resultado das datações por termoluminescência.

Tais datações vão ao encontro do apresentado na prospecção arqueológica, confirmando a presença de populações pretéritas em um espaço de tempo, variável, entre 425 AP e 215 AP.

\section{O Resgate do Sítio Arqueológico Pré-Histórico Igrejinha}

No limite ADA/AID do empreendimento está localizado o SAPH Igrejinha, coordenada 596904/7655715, em área de plantio e pasto. Durante as atividades de prospecção arqueológica foram encontrados fragmentos cerâmicos em uma extensa área, totalizando, aproximadamente 6,3 
ha. Foram realizadas intervenções em subsuperfície, porém sem resultados positivos. A princípio, os fragmentos encontrados poderiam ser considerados simples, sem decorações, com espessuras variadas e antiplástico de quartzo.

Durante o resgate arqueológico, a vegetação se encontrava bastante desenvolvida, diminuindo drasticamente a visibilidade de superfície. Quanto ao terço inferior do sítio, o local se encontrava arado, devido a uma colheita. Vale destacar que, segundo Araújo (2002, p. 9):

Nossa relação com terrenos arados é ambígua. Ao mesmo tempo em que temos nestes locais uma visibilidade ótima e, portanto, condições privilegiadas de encontrar sítios arqueológicos, além de ainda podermos visualizar claramente a distribuição das peças no espaço, a destruição aparente que presenciamos quase que instantaneamente rebaixa tais sítios a uma classe menor, à classe dos sítios perturbados.

A primeira ação foi a de estender uma malha alfa (sentido $\mathrm{N}-\mathrm{S}$ ) - numérica (sentido W-E), possibilitando, posteriormente, a coleta - georreferenciada - de superfície, no terço inferior do sítio arqueológico, local de melhor visibilidade.

Conforme explana Araújo (2002, p.10), “estudos mais recentes já demonstraram que sítios de superfície sujeitos à aradura podem fornecer dados da mais alta qualidade, em muitos casos sem necessidade de escavações". Tal afirmação pôde se confirmar após as análises em gabinete, auxiliando na fundamentação de inferências e na elaboração de possíveis teorias.

Quanto ao resultado da coleta superficial, pode-se afirmar a existência de concentrações na porção centro-sul do sítio arqueológico, sendo possível coletar 2.109 fragmentos cerâmicos. Esse resultado se deu por dois principais motivos, a saber: declividade e arado recente. Outro ponto a ser levantado é a maior concentração de material no setor sudeste do terço inferior. Ainda, esta concentração de material se estende por cerca de 100 m leste, após a delimitação do sítio arqueológico, diminuindo, gradativamente, a presença de vestígios em superfície (Figura 5). No entanto, o local, em uma cota altimétrica inferior, apresenta grande quantidade de material em subsuperfície, diferindo-se completamente do restante do sítio. 


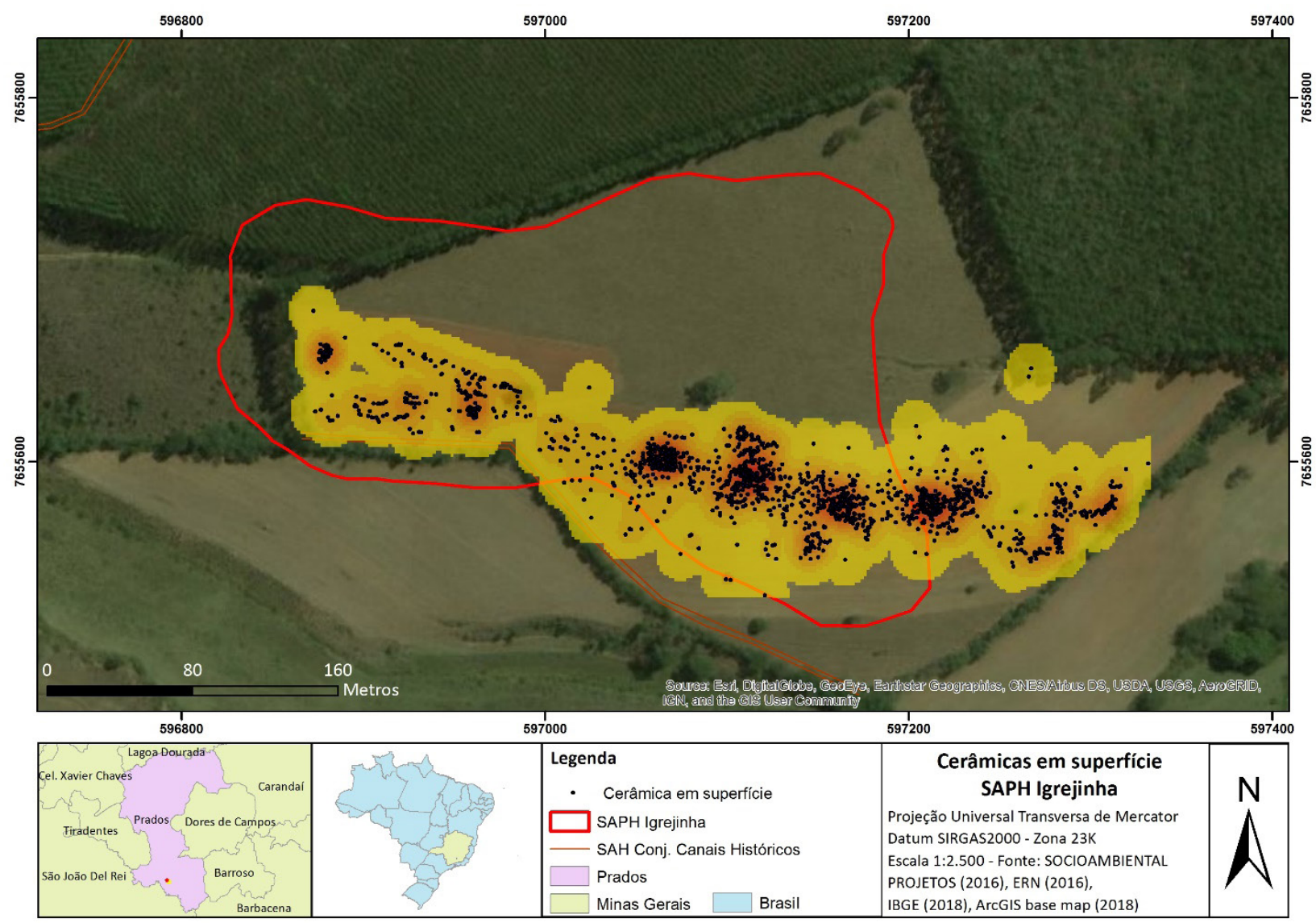

Figura 5: Coleta de material em superfície.

Com tais informações, decidiu-se, inicialmente, por realizar uma amostragem, buscando atender toda a área do sítio, realizando, assim, quadrículas de $1 \mathrm{~m}^{2}$, em malha de $40 \mathrm{~m}$ equidistantes, totalizando 45 sondagens. Posteriormente, em áreas de maior potencialidade, a malha foi estreitada a 20 m e 10 m equidistante, resultando em 32 novas tradagens.

Após a locação da sondagem e de sua delimitação, os vestígios arqueológicos em superfície eram coletados e registrados (Figura 6). Assim como no SAPH Evangelista, todas as unidades de escavação foram executadas com níveis artificiais de $10 \mathrm{~cm}$ e aprofundadas até $30 \mathrm{~cm}$ ou um nível estéreo.

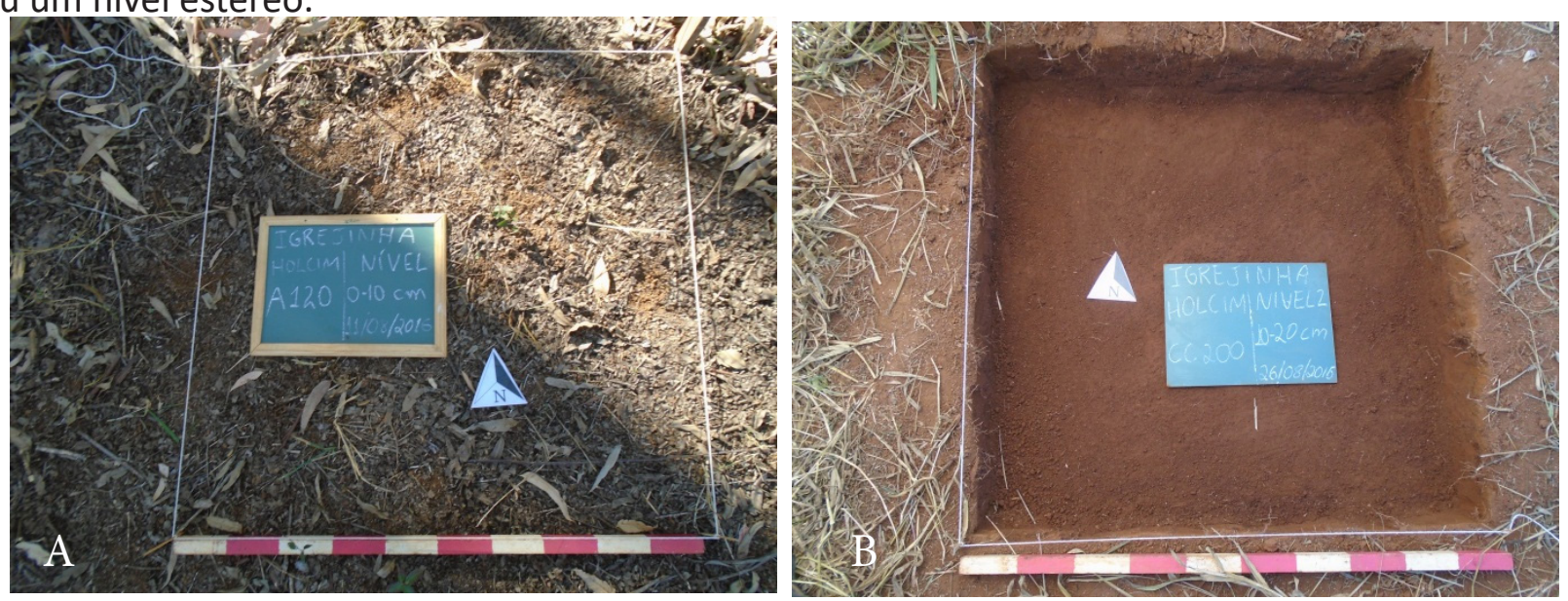

Figura 6: Sondagens realizadas. 
Para a área além da delimitação do sítio arqueológico, foram realizadas 3 sondagens, sendo duas com retorno positivo. Essas sondagens apresentaram material cerâmico até o nível $10(90-100 \mathrm{~cm})$, contrastando o local como a região de maior concentração de vestígios em subsuperfície. Finalmente, é importante destacar que não foram realizadas novas intervenções próximas às sondagens positivas devido a questões contratuais. Dessa forma, o local se encontra bastante preservado, sendo possível resgatar o maior número de informações possíveis em pesquisas posteriores (Figura 7).
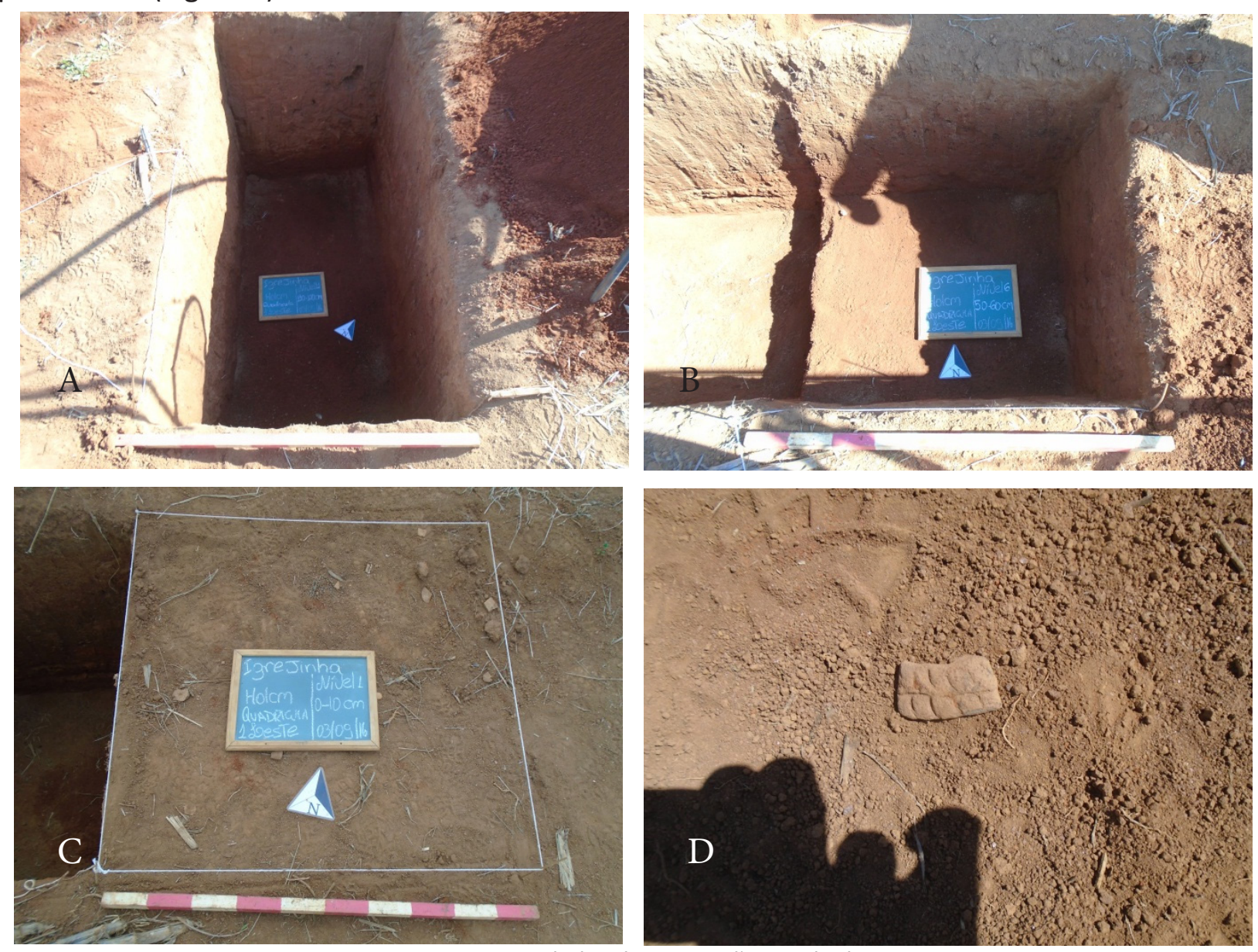

Figura 7: Unidades de escavação ampliadas.

Do total de 87 unidades de escavação abertas, 52,87\% apresentaram resultado positivo em um ou mais níveis quanto à presença de material arqueológico. Tal resultado difere bastante do SAPH Evangelista, que retornou mais de $80 \%$ de sondagens positivas. Desse modo, a análise dos resultados permite inferir a baixíssima presença de material cerâmico em subsuperfície.

Dentre as unidades de escavação e material em superfície foram exumados cerca de 3.000 fragmentos, no entanto, após descarte de material inapto para análises, totalizou uma quantidade de 2.584 fragmentos cerâmicos. Como pode ser notado em gráficos a seguir, há uma maior concentração de cerâmicas, em subsuperfície, encontradas nas linhas " $A$ " (engloba A; I; J; T e $\mathrm{U})$ e " $\mathrm{H}$ ", o que mostra uma maior concentração de vestígios arqueológicos no terço superior e no terço inferior do sítio arqueológico. 


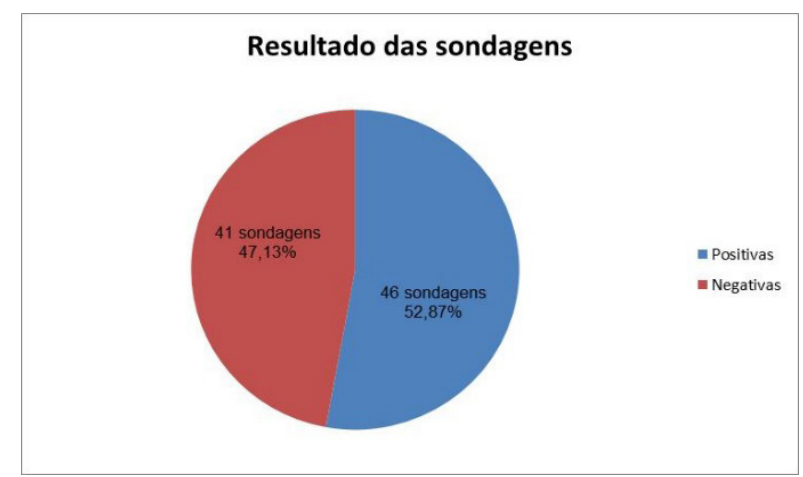

Gráfico 3: Resultado das sondagens

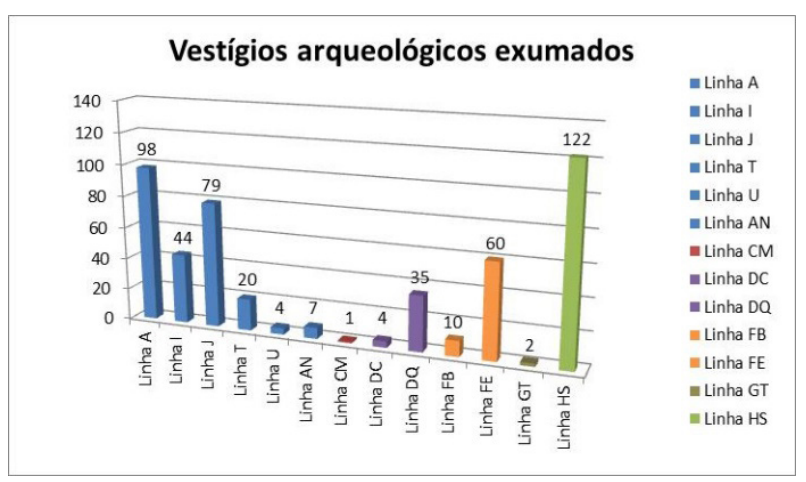

Gráfico 4: Cerâmicas exumadas por linhas

Após análises aprofundadas, é possível inferir que o material se caracteriza por apresentar modo de produção acordelado; acabamento polido e/ou engobo vermelho; núcleo escuro ou núcleo central escuro; antiplástico mineral. Tais materiais se encontram bastante fragmentados devido às constantes ações de preparo de terra para gado e plantio. Como pôde se perceber, a camada arqueológica, na maior parte do sítio, limita-se aos dois primeiros níveis, sendo que em apenas seis sondagens foram encontrados vestígios arqueológicos abaixo de $30 \mathrm{~cm}$.

Visto a quantidade de material encontrado, foram coletados dois fragmentos cerâmicos para datação por termoluminescência (DQ320, nível 2 - 10-20 cm / HS400, nível 5 - 40-50 cm). Para tais fragmentos, foram apresentadas as seguintes datações:

\begin{tabular}{|c|c|c|c|c|}
\hline Cód. Datação & Amostra & Dose Anual & Dose Acumulada & Idade (anos) \\
\hline \multicolumn{5}{|c|}{ Datação do Resgate Arqueológico } \\
\hline 4676 & HS400-40-50 cm & $3.900 \pm 450$ & 2,6 & $670 \pm 110$ \\
\hline 4680 & DQ320 - $10-20 \mathrm{~cm}$ & $5.400 \pm 590$ & 5,1 & $950 \pm 150$ \\
\hline \multicolumn{5}{|c|}{ Datação da Prospecção Arqueológica } \\
\hline 4382 & Sítio Igrejinha $-0-10 \mathrm{~cm}$ & $2.180 \pm 275$ & 1,1 & $500 \pm 90$ \\
\hline
\end{tabular}

Tabela 2: Resultado das datações por termoluminescência.

Tais datações vão ao encontro da obtida na prospecção arqueológica, confirmando a presença de populações pretéritas em um espaço de tempo, variável, entre 1100 AP e 410 AP, intervalo maior do que o apresentado no sítio Evangelista.

\section{RESULTADOS OBTIDOS}

Os artefatos exumados dos SAPH Evangelista e Igrejinha passaram por uma triagem visando ao descarte de material inapto para análise. Posteriormente, o material foi separado e quantificado. Isto feito, iniciou-se a higienização sistemática da cerâmica, atentando-se à metodologia utilizada por Soares, Salvador \& Biléssimo (2013, p.29), por meio da qual a cerâmica deve ser "higienizada em água com a ponta dos dedos, e/ou, quando necessário, escova macia". Além disso, segundo os autores, "emprega-se menor quantidade de água possível para lavar estes 
materiais, uma vez que em grande quantidade, ou mesmo a imersão, pode facilitar quebras ou descascamentos de peças frágeis" (SOARES, SALVADOR \& BILÉSSIMO, 2013, p.29).

\section{Análise Laboratorial}

Os atributos observados na análise do material se basearam em dados métricos, dados tecnológicos e dados morfológicos, a saber: espessura; técnica de manufatura; antiplástico; tratamento de superfície; núcleo; tipo de corpo; tipo de base; tipo de borda; tipo de lábio, dentre outros. A análise seguiu a metodologia pré-definida, assim como os procedimentos apresentados por Henriques Júnior (2006), Corrêa (2009) e Cavalcante, Fabris \& Araújo (2015). Ressalta-se que os vestígios resgatados apresentaram potencial interpretativo e informações de extrema importância para a contextualização em que os sítios arqueológicos estão inseridos.

As técnicas utilizadas para a manufatura dos artefatos cerâmicos podem auxiliar diretamente na compreensão das possibilidades de produção utilizadas por esses atores. Tais técnicas se dividem em: acordelado; modelado; torneado e moldado. Para os sítios arqueológicos em questão, grande parte dos fragmentos são acordelados, no entanto, é muito comum também aparecerem artefatos produzidos com a técnica do modelado.

Já o antiplástico foi analisado visto a sua importância para a liga da argila e a possibilidade de se realizar uma boa queima. A classificação dos materiais utilizados foi feita da seguinte forma: mineral; caco moído; cariapé; concha; carvão; cauxi e bolo de argila.

Foram analisadas tanto as superfícies externas quanto as internas. Essas características podem auxiliar os pesquisadores a compreenderem diversas questões, a exemplo de fatores sociais. Para tal, o tratamento de superfície externo foi dividido em: alisado; corrugado; ungulado; escovado; pintado; inciso; estocado; dentre outros. Já o tratamento de superfície foi dividido em: alisado; polido; resina; esfumarado; pintado; banho vermelho; engobo branco; engobo vermelho.

Os núcleos das peças foram divididos em: cor uniforme clara; cor uniforme escura; núcleo central escuro; camada escura próxima à superfície interna; camada escura próxima à superfície externa (CORRÊA, 2009).

Prous (1992) e Milheira, Farias \& Alves (2013) relacionam a coloração do núcleo com o tipo de queima a que a cerâmica é submetida. A queima redutora, possivelmente em forno aberto, ocorre em temperaturas menores que $700{ }^{\circ} \mathrm{C}$, ocasionando a retenção do carbono presente no interior da peça, o que resulta em um vasilhame com coloração escura e núcleo de coloração preta ou acinzentada (MILHEIRA, FARIAS \& ALVES, 2013).

Já em relação aos dados morfológicos, a análise foi dividida em: tipo de corpo; tipo de base; tipo de borda; tipo de lábio. Prous (1992, p. 95) define essas características morfológicas da seguinte maneira:

Chama-se base ao fundo, que pode ser plano, arredondado, com pés ou pedestal, etc. A parte central é chamada de bojo (aqui chamado de corpo); 
quando o seu diâmetro maior apresenta uma brusca inflexão angular, dizse que o bojo é carenado. A borda é a parte terminal do pote junto à boca. A extremidade da borda, por onde corre o conteúdo quando a vasilha fica inclinada, é chamada lábio.

Isto posto, seguem abaixo os resultados obtidos com as análises laboratoriais.

Em relação à categoria dos vestígios arqueológicos, pode-se afirmar, para ambos os sítios, uma maior quantidade de fragmentos de corpo mesial, ou seja, a parte do vaso também conhecida como parede ou bojo. Dessa forma, para o SAPH Evangelista, a contabilização dos fragmentos foi: 1140 fragmentos de corpo mesial (90\%), além de 127 fragmentos de borda (10\%). Já para o SAPH Igrejinha, a contabilização dos fragmentos apresenta 2319 fragmentos de corpo mesial (90\%), além de 264 fragmentos de borda (10\%) e um fragmento de base.

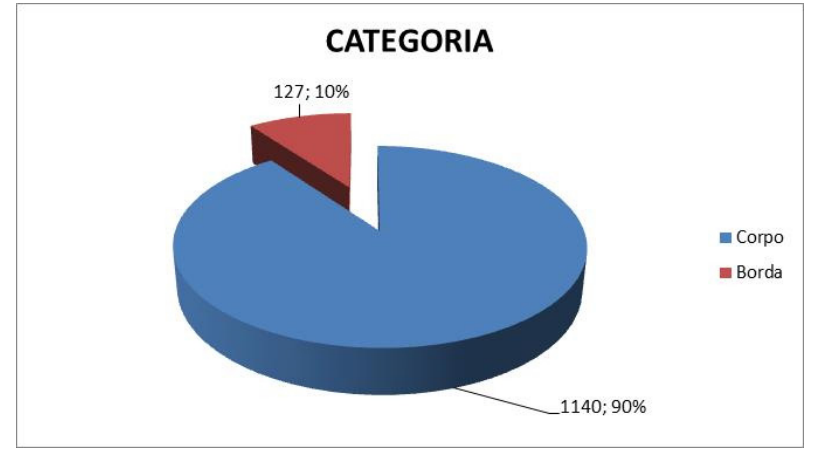

Gráfico 5: Fragmentos por categoria. SAPH Evangelista

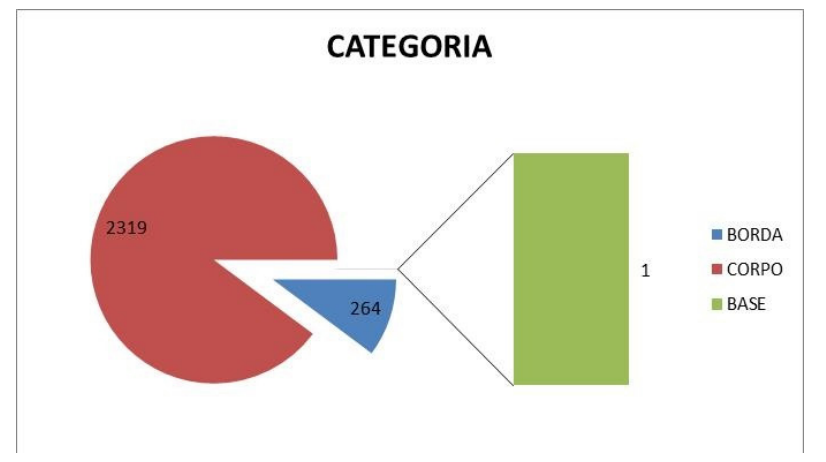

Gráfico 6: Fragmentos por categoria. SAPH Igrejinha

Em relação ao SAPH Evangelista (Figura 8), do total de fragmentos de bordas, a maior quantidade é de fragmentos introvertidos (89 fragmentos - $70 \%$ ), seguidos de bordas diretas (22 fragmentos - 17\%), bordas extrovertidas (15 fragmentos - 12\%) e borda reforçada interna e externamente (1 fragmento). Já em relação ao SAPH Igrejinha, a maior quantidade é de fragmentos diretos (184 fragmentos - $70 \%$ ), seguidos de bordas introvertidas (74 fragmentos - 28\%) e bordas extrovertidas (6 fragmentos - $2 \%$ ).
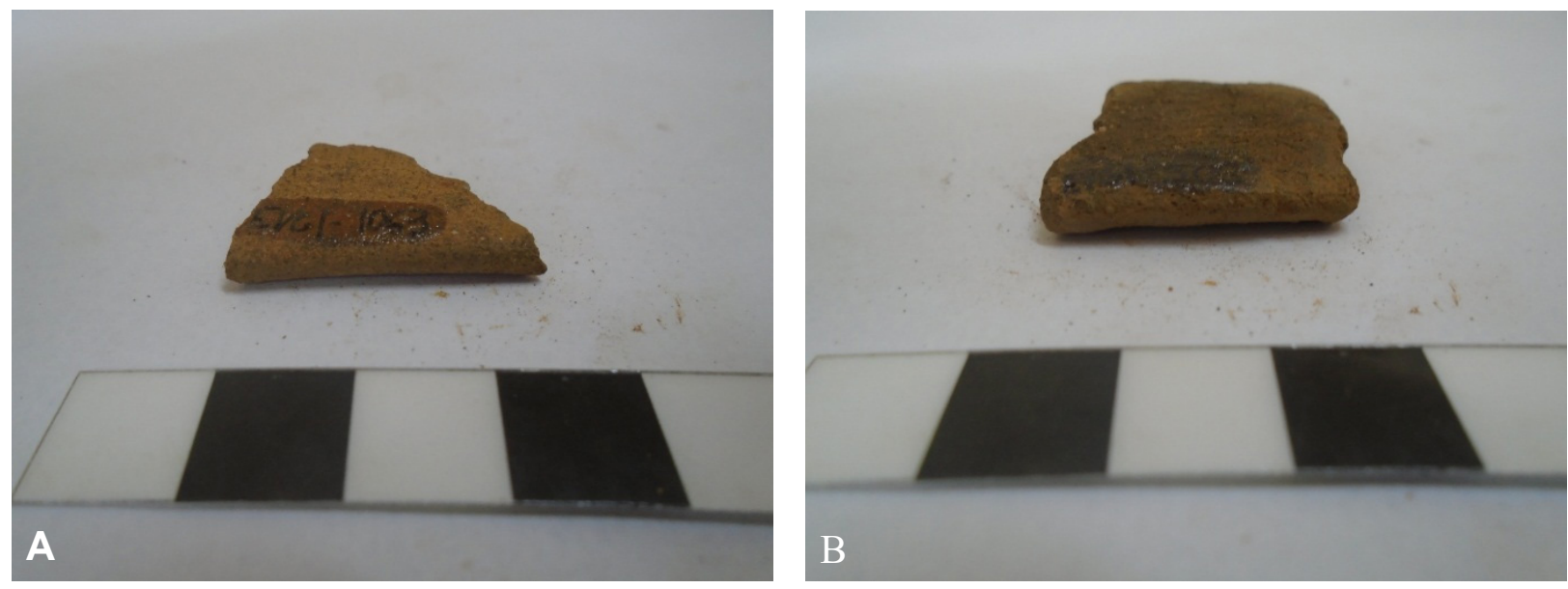

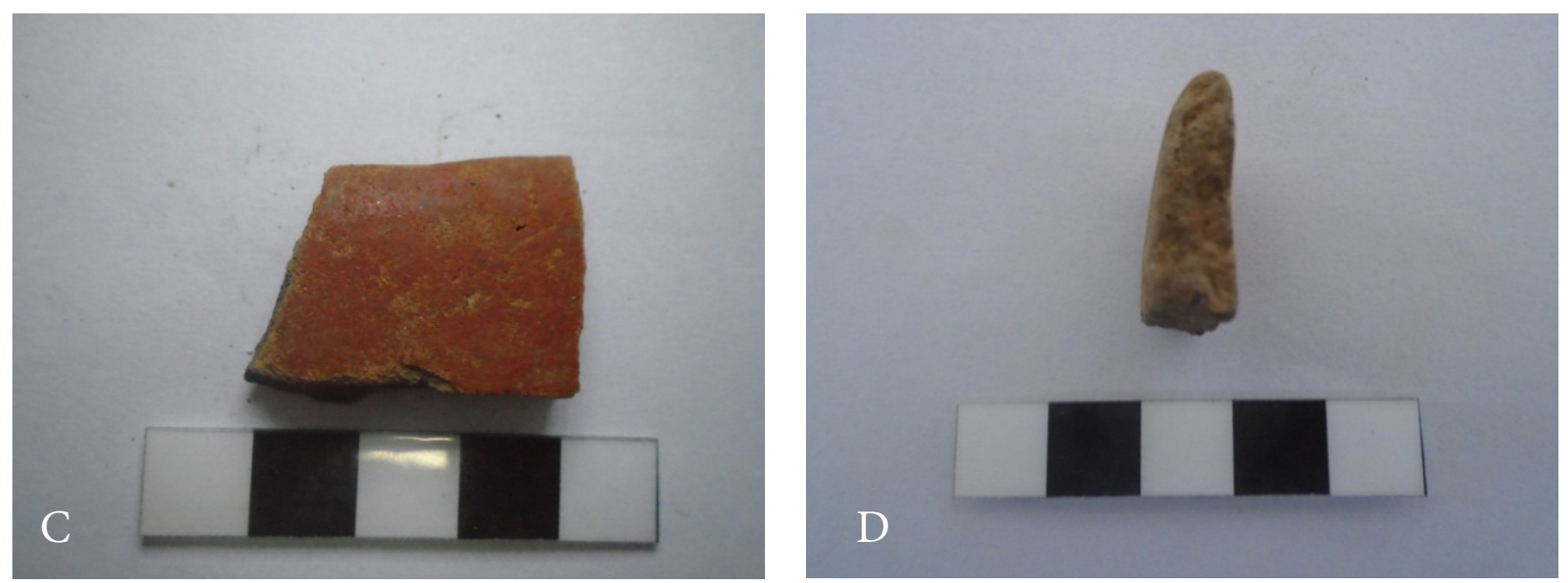

Figura 8: Tipos de borda. A-B: SAPH Evangelista. C-D: SAPH Igrejinha.

Quanto às técnicas utilizadas para manufatura, no SAPH Evangelista, predomina o acordelamento revelado pelo padrão de fratura quadrangular, verificado em 534 dos fragmentos (42\%). Apesar da tentativa de identificar as demais técnicas (modelado, torneado e moldado), a maior parte dos fragmentos não apresentaram possibilidade de leitura, retornando um número de 733 peças (58\%). O mesmo acontece para SAPH Igrejinha, que apresenta o acordelamento em 2074 fragmentos (80\%), sendo que as demais não apresentaram possibilidade de leitura (510 peças $20 \%)$.

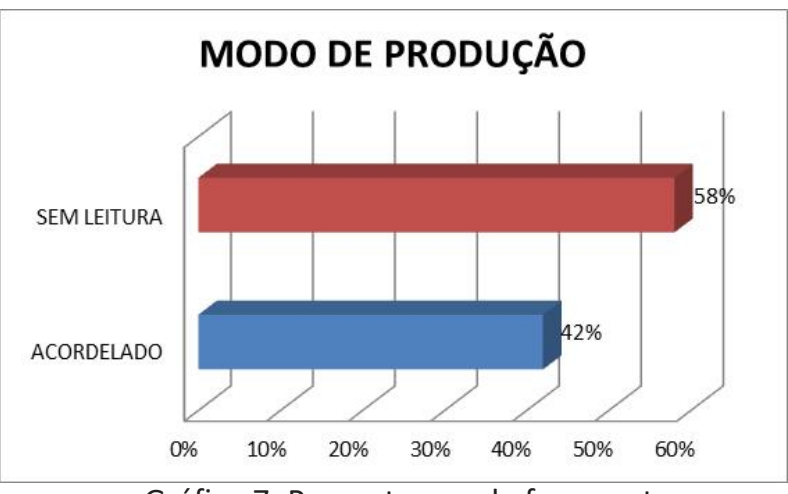

Gráfico 7: Porcentagem de fragmentos por modo de produção - SAPH Evangelista.

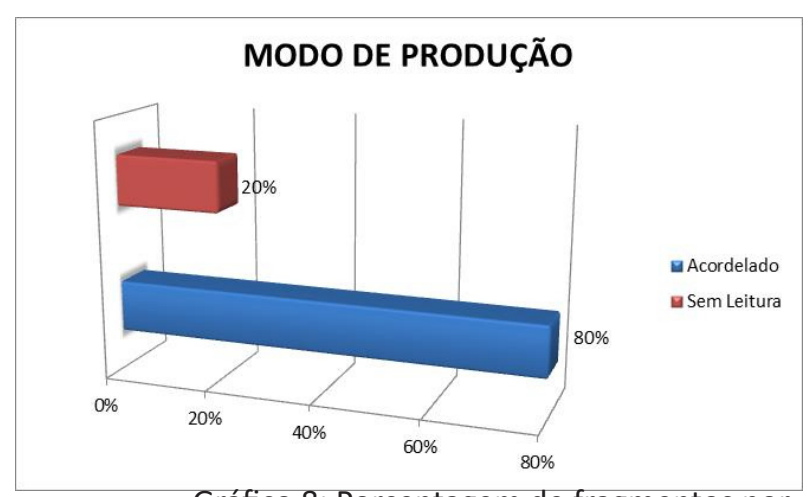

Gráfico 8: Porcentagem de fragmentos por modo de produção - SAPH Igrejinha.

No que se refere à espessura dos fragmentos, para o SAPH Evangelista, pendeu-se para fragmentos considerados finos (espessura $<10 \mathrm{~mm}$ ). Foram exumados 133 fragmentos com espessura entre 3 e 4,99 mm (11\%); 935 fragmentos com espessura entre 5 e 9,99 mm (73\%); 184 fragmentos com espessura entre 10 e 14,99 mm (14\%); 14 fragmentos com espessura entre 15 e 19,99 mm (1,9\%) e 1 fragmento com espessura entre 20 e 24,99 mm (0,1\%). O SAPH Igrejinha seguiu o mesmo padrão, apresentando 82 fragmentos com espessura entre 3 e 4,99 mm (3,45\%); 1537 fragmentos com espessura entre 5 e 9,99 mm (59\%); 874 fragmentos com espessura entre 10 e 14,99 mm (34\%); 89 fragmentos com espessura entre 15 e 19,99 mm (3,5\%); 1 fragmento com espessura entre 20 e $24,99 \mathrm{~mm}(0,05 \%)$. 
Dessa forma, é possível notar que houve uma maior presença de fragmentos considerados finos ou muito finos $(<10 \mathrm{~cm}$ ), que necessitam de maior destreza por parte da(o) artesã(o). Conforme Panachuk (2005, p. 69), a simetria pode indicar graus diferenciados de destreza e habilidade desses atores, onde "a recorrência de fragmentos menores que $1 \mathrm{~cm}$ de espessura (...) parece apontar para um traço social desta produção, uma escolha social mantida com rigor".

Quanto ao antiplástico, foram identificados elementos de origem mineral e vegetal, com predominância do primeiro grupo. Os componentes encontrados foram: quartzo, caco-moído e argila. Para o SAPH Evangelista, dentre os 1267 fragmentos cerâmicos, 1239 apresentam quartzo, 2 apresentam caco-moído; 25 apresentam uma combinação entre argila e quartzo; 1 apresentou combinação entre caco-moído, quartzo e argila. Já para o SAPH Igrejinha, dentre os 2584 fragmentos cerâmicos, 2582 apresentam quartzo, 1 apresentou caco-moído; 1 apresentou uma combinação entre argila e quartzo. Há também a presença de elementos de origem vegetal, no entanto, a presença desse material se dá de forma menos intensa do que a do mineral (Figura 9).
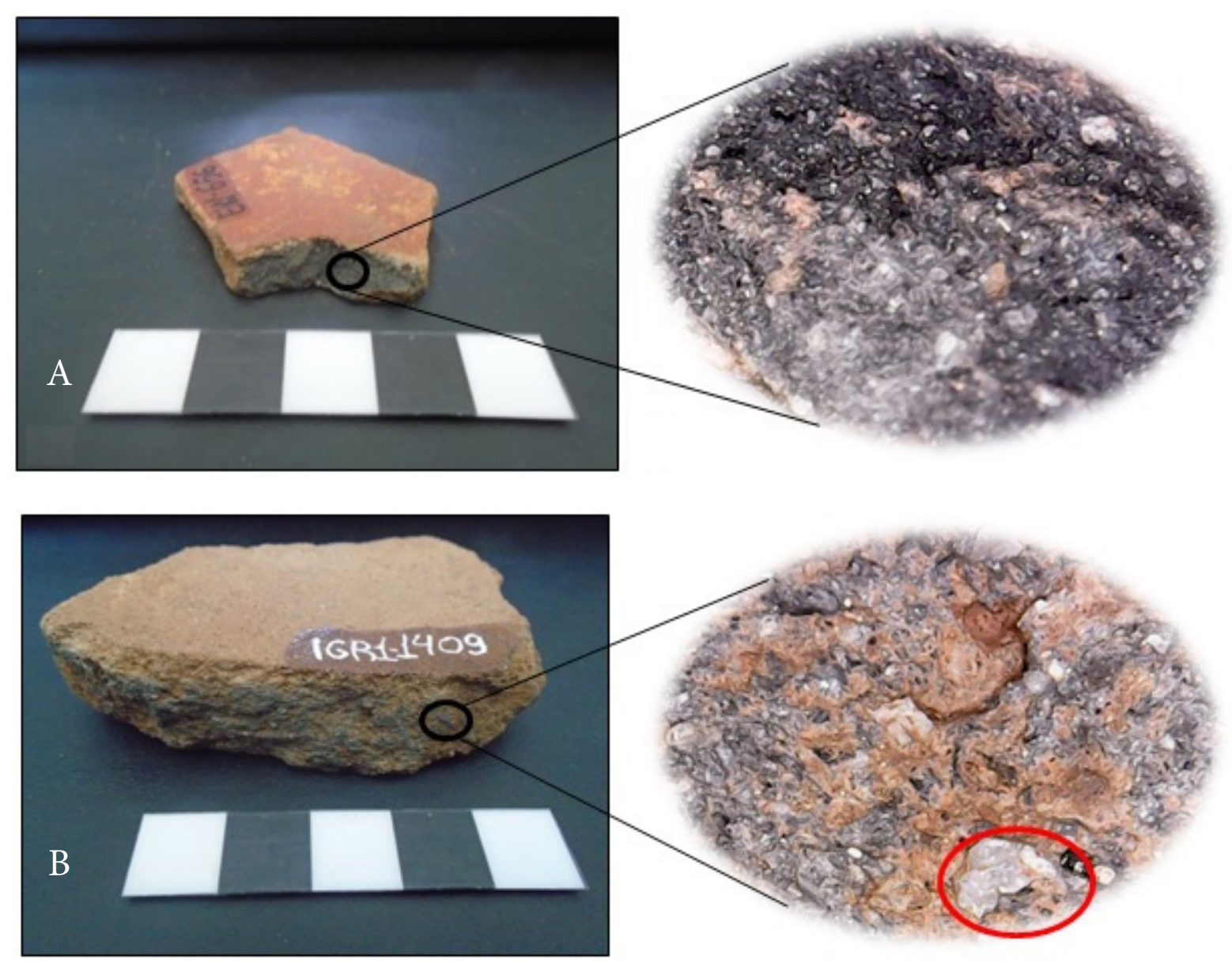

Figura 9: Fragmento cerâmico - Análise microscópica. A: SAPH Evangelista. B: SAPH Igrejinha.

O tratamento de superfície foi subdividido em superfície externa e superfície interna, sendo ambas as porções das peças analisadas. Em relação ao SAPH Evangelista (Figura 10), para a superfície externa, apresentaram-se os seguintes tratamentos: alisado (365 fragmentos - 29\%), polido (781 fragmentos - 61\%), engobo vermelho (112 fragmentos - $9 \%$ ), sem leitura ( 9 fragmentos - 
<1\%). Já para o SAPH Igrejinha apresentaram-se os seguintes tratamentos: alisado (738 fragmentos $30 \%$ ), polido (1636 fragmentos - 36\%), engobo vermelho (148 fragmentos - $6 \%$ ), inciso ( 2 fragmentos - 0,07\%), corrugado (1 fragmento - 0,03\%), sem leitura (14 fragmentos - $1 \%$ ).

Torna-se digno de nota que o tratamento de superfície interna segue o mesmo padrão apresentado pelo tratamento de superfície externa, sendo o polido como principal técnica, seguido de longe pelo alisado. Dessa forma, para o SAPH Evangelista, apresentaram-se os seguintes tratamentos: alisado (348 fragmentos - 28\%), polido (898 fragmentos - 70\%), engobo vermelho (8 fragmentos - 1\%), sem leitura (13 fragmentos - 1\%). Já para o SAPH Igrejinha: alisado (830 fragmentos - 32\%), polido (1708 fragmentos - 66\%), engobo vermelho (25 fragmentos - 1\%), sem leitura (21 fragmentos - $1 \%)$.
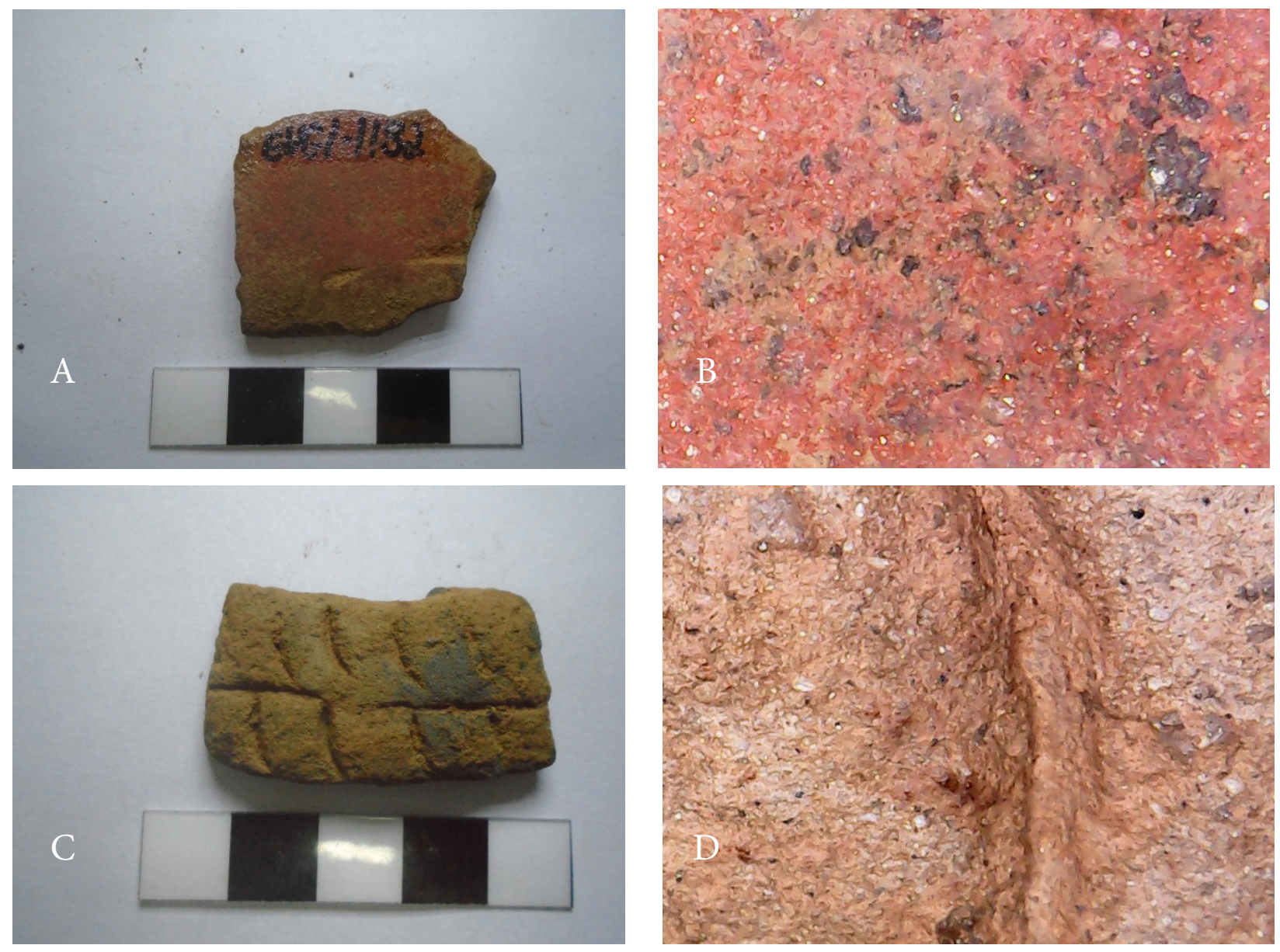

Figura 10: Tratamento de superfície. A-B: Engobo Vermelho - SAPH Evangelista. C-D: Corrugado - SAPH Igrejinha

Quanto aos tipos de núcleo, foi utilizada a metodologia de análise de Corrêa (2009). No entanto, entende-se que a forma de queima pode influenciar diretamente na coloração do núcleo cerâmico (MILHEIRA, FARIAS \& ALVES, 2013). Dessa maneira, após análise de todos os fragmentos cerâmicos, para o SAPH Evangelista, o resultado foi: núcleo claro (222 fragmentos - 18\%), núcleo escuro (879 fragmentos - 69\%), núcleo centro escuro (113 fragmentos - 8,9\%), núcleo superfície interna escura (45 fragmentos - 3,5\%), núcleo superfície interna clara (8 fragmentos - 0,6\%). Já o 
SAPH Igrejinha retornou o seguinte resultado: núcleo claro (354 fragmentos - 14\%), núcleo escuro (1599 fragmentos - 62\%), núcleo centro escuro (431 fragmentos - 17\%), núcleo superfície interna escura (178 fragmentos - 6\%), núcleo superfície interna clara (21 fragmentos - 1\%), sem leitura (1 fragmento - 1\%). Cabe salientar que os artefatos provenientes de queima redutora apresentam uma menor resistência térmica e mecânica (PANACHUK, 2005), demonstrando um núcleo cerâmico de coloração escura.

Finalmente, foram realizadas representações gráficas amostrais de fragmentos cerâmicos através do programa Adobe Illustrator (Figura 11).

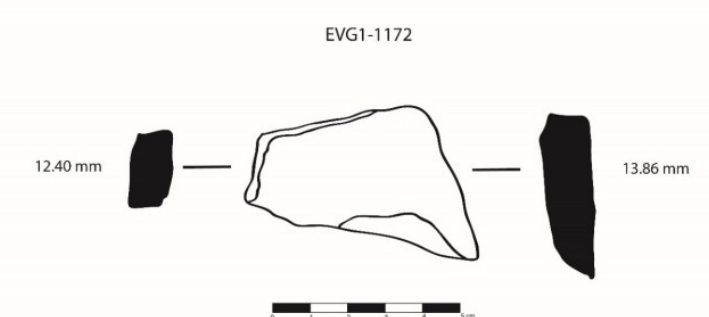

A

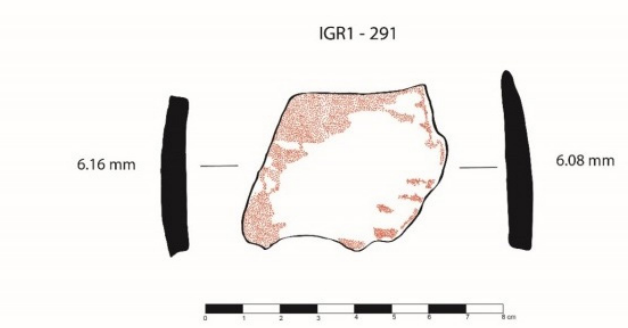

C

Figura 11: Representações gráficas. A-B: Cerâmicas SAPH Evangelista. C-D: Cerâmicas SAPH Igrejinha.

\section{Correlação entre os Sítios Arqueológicos}

Para melhor compreensão do contexto de ocupação pré-colonial local, buscou-se averiguar a possibilidade de os sítios arqueológicos fazerem parte de um mesmo momento de ocupação ou terem alguma correlação. Assim, buscando cobrir a distância entre os dois sítios $(175 \mathrm{~m})$, foram escavadas 2 linhas com 5 sondagens cada (a cada $30 \mathrm{~m}$ ). Das dez sondagens abertas, apenas duas apresentaram resultados positivos, sendo uma em cada extremo. Dessa forma, há um hiato de cerca de $150 \mathrm{~m}$ sem presença de vestígios arqueológicos.

Outra razão para esse resultado seria o deslocamento massivo de sedimento a fim de preparo da área para plantio, levando consigo o material arqueológico. Tal situação poderia ter ocorrido através do deslocamento de sedimento do terço superior para o terço inferior, onde se 
localiza o SAPH Evangelista. No entanto, a existência de ramificação do SAH Conjunto de Canais Históricos, entre os sítios arqueológicos, impossibilita essa teoria.

Ainda, intentou-se correlacionar os sítios através das datações por termoluminescência. A análise temporal, realizada no âmbito do resgate arqueológico, levando em consideração a variação de datas das amostragens, permitiu chegar a um período de ocupação simultânea de aproximadamente 15 anos, considerando que a datação do SAPH Evangelista seja considerada como 425 anos AP (370+55), enquanto a datação do SAPH Igrejinha seja considerada 410 anos AP (50090). Considerando tais números, pode-se inferir uma coexistência ou ocupação simultânea. Não obstante, torna-se impossível realizar quaisquer informações quanto a essas questões sem uma análise aprofundada de ambos os sítios arqueológicos e de suas materialidades.

\section{CONSIDERAÇÕES FINAIS}

O levantamento arqueológico do município de Prados/MG, trouxe à luz a riqueza local em relação a vestígios materiais de populações pré-coloniais.

Os fragmentos cerâmicos exumados nos sítios caracterizam-se por sua espessura fina (menor que $10 \mathrm{~mm}$ ), tratamento de superfície externa e interna polida, antiplástico mineral, núcleo predominantemente escuro e técnica de manufatura por acordelamento. Grande parte desses fragmentos assemelha-se às características dos artefatos cerâmicos identificados na tradição Aratu/Sapucaí. Tais informações, aliadas às anteriormente expostas, possibilitam inferir a ocupação concomitante de ambos os sítios, mesmo que por um pequeno período de tempo.

Entende-se ainda que os sítios arqueológicos não foram escavados à exaustão, porém, na Arqueologia Preventiva - infelizmente - há a necessidade de se propor limites à escavação. Desse modo, com esta pesquisa intentou-se a realização de um trabalho de qualidade que retornasse quantidade de informação considerável para uma análise posterior e para a compreensão da relação desse sítio com os encontrados em suas proximidades. Vale salientar, por fim, que os sítios serão monitorados durante a expansão do empreendimento. 


\section{REFERÊNCIAS}

ARAUJO, Astolfo Gomes de Mello. Destruído pelo arado? Arqueologia de superfície e as armadilhas do senso comum. Revista de Arqueologia, São Paulo: SAB, v. 14-15, p. 07-28, 2001-2002.

CAVALCANTE, Luis Carlos Duarte; FABRIS, José Domingos; ARAÚJO, Igor Linhares de. Estudo arqueométrico de cerâmicas arqueológicas do Sítio Lagoa do Portinho. Revista Clio Arqueológica, Recife: UFPE, v. 30, n. 2, p. 189-240, 2015.

CORRÊA, Ângelo Alves. Tetama nas matas mineiras: Sítios Tupi na microrregião de Juiz de Fora - MG. Dissertação de Mestrado. São Paulo: MAE-USP, 2009.

HENRIQUES JUNIOR, Gilmar Pinheiro. Arqueologia Regional da Província Cárstica do Alto São Francisco. Um estudo das tradições ceramistas Una e Sapucaí. Dissertação de Mestrado. São Paulo: MAE-USP, 2006.

MELO, Paulo Jobim Campos. Escavação por amostragem: exemplos dos sítios GO-CA-21 e AM-CO04. Revista de Divulgação Científica, Goiânia: IGPA/UCG, v. 3, p. 153-163, 1999.

MILHEIRA, Rafael Guedes; FARIAS, Deisi Scunderlick Eloy de; ALVES, Luana. Perfil tipológico da indústria cerâmica Guarani da região sul de Santa Catarina. Revista Tempos Acadêmicos, Dossiê de Arqueologia Pré-histórica, Criciúma: UNESC, n 11, p. 210-233, 2013.

PANACHUK, Lílian. Metodologia de análise e objetivos dos procedimentos quantitativos. In: SCIENTIA CONSULTORIA CIENTÍFICA. Projeto Salvamento arqueológico Sítio Arqueológico RPO-1, São Mateus - ES. São Paulo: Scientia, 2005, p. 61-66.

PROUS, André. Arqueologia Brasileira. Brasília: UNB, 1992.

SCIENTIA CONSULTORIA CIENTÍFICA. Projeto Salvamento dos sítios arqueológicos na área diretamente afetada da Linha de Transmissão Tucuruí/PA - Presidente Dutra/MG ( ${ }^{\circ}$ circuito). São Paulo: Scientia/EATE, 2002.

- Projeto Salvamento arqueológico Sítio Arqueológico RPO-1, São Mateus - ES. São Paulo: Scientia, 2005.

SOARES, Fernanda Codevilla; SALVADOR, Angela; BILÉSSIMO, Angelo Renato. Inventário do acervo arqueológico das fortificações catarinenses. Revista Tecnologia e Ambiente, Dossiê IX Jornadas de Arqueologia Iberoamericana e I Jornada de Arqueologia Transatlântica, Criciúma: UNESC, v. 19, n.1, p. 17-38, 2013.

SOCIOAMBIENTAL PROJETOS. Relatório de Resgate Arqueológico mina Fazenda Invernada e Mata do Ribeirão. Belo Horizonte: CONSULTORIA, 2016.

SUGUIMATSU, Isabela Cristina; SYMANSKI, Luís Cláudio Pereira. Atividades cotidianas, deposição de refugo e ação do arado: processos de formação do registro arqueológico no espaço de uma senzala de Campos dos Goytacazes (RJ). Revista Clio Arqueológica, Recife: UFPE , v. 30, n. 1, p. 38-78, 2015.

VIANA, Sibele Aparecida. Análise Espacial Intra-Sítio: o estudo do Sítio Lourenço (GO-CA-14). Revista de Arqueologia, São Paulo: SAB, v. 9, p. 65-87, 1996. 